\title{
PerCursos
}

\section{Pensamento indígena e conhecimento histórico: reflexões acerca das funções do ensino de história}

\begin{abstract}
Resumo
O objetivo deste artigo é pensar possíveis diálogos entre a produção teórica de autores indígenas e o ensino de história, intenção que é fundamentada, entre outras coisas, a partir das demandas impulsionadas pela Lei 11.645/2008. Tal medida tornou obrigatório, em 2008, o estudo dos povos indígenas nas instituições de ensino brasileiras. A estrutura do texto se divide em duas partes; a primeira contextualiza e analisa aspectos relativos à lei e também às suas Diretrizes Operacionais, publicadas em 2016. A segunda parte se dedica a aprofundar os aspectos teóricos do ensino de história indígena com base nas discussões apresentadas pela educação histórica, focando na perspectiva das narrativas indígenas e suas contribuições para a historiografia e o ensino. Assim, o texto se centra nas duas dimensões do ensino de história indígena, que são tanto a sua função social quanto cognitiva, e para isso se utiliza de autores como Ailton Krenak, Gersem Baniwa e Peter Lee.
\end{abstract}

Palavras-chave: Lei 11.645/2008. Autores indígenas. Ensino de história.

\author{
Kerollainy Rosa Schütz \\ Doutoranda em História pela \\ Universidade Federal de Santa \\ Catarina - UFSC. \\ Brasil \\ hstkeroll@gmail.com
}

\section{Para citar este artigo:}

SCHÜTZ, Kerollainy Rosa. Pensamento indígena e conhecimento histórico: reflexões acerca das funções do ensino de história. PerCursos, Florianópolis, v. 22, n.48, p. 154 - 173, jan./abr. 2021.

DOI: $10.5965 / 1984724622482021154$

http://dx.doi.org/10.5965/1984724622482021154 


\title{
Indigenous thinking and historical knowledge: reflections on the functions of history teaching
}

\begin{abstract}
This paper's objective is thinking about the possible dialogues between theoretical production of indigenous authors and History's teaching, an intention that is based on the demands driven by the 11.645/2008 law. This legal measure has made the study of indigenous peoples in Brazilian educational institutions mandatory in 2008. The text structure is divided between two parts: the first one contextualizes and analyzes some aspects related to the law and also to its Operational Guidelines, published in 2016. The second part is dedicated to deepen the theoretical features of teaching indigenous History based on the discussions presented for historical education, focusing on the perspective of indigenous narratives and their contributions to historiography and teaching. Thus, the present text focuses on the two dimensions of teaching indigenous history, which are both its social and cognitive function, and to achieve this aim, it based on indigenous authors as Ailton Krenak, Gersem Baniwa and Peter Lee.
\end{abstract}

Keywords: Law 11.645/ 2008. Indigenous authors.

History teaching. 


\section{Considerações iniciais}

Este artigo tem por objetivo abordar a emergência do ensino de história indígena no contexto do tempo presente no Brasil, a partir da Lei 11.645/2008, refletindo principalmente acerca das funções que Ihes são atribuídas no campo teórico. Nesse sentido, o debate se dedica a pensar a emergência das narrativas indígenas como um caminho para a produção do conhecimento histórico, levando em consideração os pressupostos para uma educação histórica.

O texto está dividido em duas partes principais. Em primeiro lugar, a Lei 11.645/2008 é apresentada em sua relação com outros documentos oficiais que são a ela associados, de modo que nos possibilite compreender o contexto histórico que levou a sua implementação. Em um segundo momento, serão destacados e aprofundados alguns aspectos teóricos em potencial para a aplicação da lei, com base nas "Diretrizes Operacionais para a implementação da história e das culturas dos povos indígenas na Educação Básica, em decorrência da Lei n 11.645/2008”, pensando então os rebatimentos do ensino de história indígena no fazer historiográfico.

\section{Lei 11.645/2008: contexto de implementação e sua relação com outras políticas públicas}

Com a Constituição Federal de 1988, popularmente conhecida como constituição cidadã, os povos indígenas tiveram pela primeira vez na história do Brasil suas estruturas sociais próprias reconhecidas. Assim, no campo teórico, o documento aboliu a política de integração dos povos nativos que havia se iniciado logo nos primeiros anos de colonização, contexto este em que havia se construído a crença equivocada de que os povos indígenas poderiam ser aculturados ou extintos.

Estudos de matriz histórica, antropológica e arqueológica, para citar somente alguns campos de conhecimento, já comprovaram que tanto a concepção de aculturação é infundada, quanto por outro lado, as conquistas impulsionadas pelo movimento indígena nas últimas décadas têm como resultado o crescimento da população indígena 
autodeclarada no Brasil. Nesse sentido, o artigo 231 da Constituição Federal de 1988 é um exemplo da importância do documento:

Art. 231. São reconhecidos aos índios sua organização social, costumes, línguas, crenças e tradições, e os direitos originários sobre as terras que tradicionalmente ocupam, competindo à União demarcá-las, proteger e fazer respeitar todos os seus bens. (BRASIL, 1988 p. 133)

Há, como vemos, uma garantia legal por parte da Constituição Federal às estruturas sociais indígenas em sua totalidade, cabendo ao Estado iniciativas que viabilizem a manifestação das especificidades dos diferentes povos indígenas ao longo de todo o território brasileiro. Território este que é constituído, muito antes de ser uma divisão geopolítica do Estado Brasileiro, por territórios tradicionais. Outra conquista é o ensino diferenciado que se materializa nas escolas indígenas em todo o país.

Já em relação ao cenário mais amplo do ensino regular, que é neste caso constituído em maioria pelos não indígenas, a Lei de Diretrizes e Bases (LDB) publicada no ano de 1996 (Lei 9.394/1996), também pode ser considerada como uma parte desse processo, na medida em que incluiu o estudo dos povos indígenas no conjunto de temáticas transversais, avanço sem precedentes no ensino regular. Mas, em 2003, esse processo se fortaleceu com a implementação da Lei 10.639/2003 que alterou a LDB, pois o estudo dos povos africanos e afro-brasileiros se tornou, então, obrigatório. Cinco anos depois, em 2008, a medida foi modificada novamente, dessa vez para a inclusão da temática indígena como obrigatória nas escolas, com a implementação da lei que passou a ser identificada como 11.645/2008:

Art. 26-A. Nos estabelecimentos de ensino fundamental e de ensino médio, públicos e privados, torna-se obrigatório o estudo da história e cultura afro-brasileira e indígena. $\oint 1^{\circ}$ O conteúdo programático a que se refere este artigo incluirá diversos aspectos da história e da cultura que caracterizam a formação da população brasileira, a partir desses dois grupos étnicos, tais como o estudo da história da África e dos africanos, a luta dos negros e dos povos 
indígenas no Brasil, a cultura negra e indígena brasileira e o negro e o índio na formação da sociedade nacional, resgatando as suas contribuições nas áreas social, econômica e política, pertinentes à história do Brasil. (BRASIL, 2008, art. 26-a)

O novo status conferido aos povos de origem africana e indígena na educação brasileira impulsionou o planejamento e o desenvolvimento de estratégias que efetivassem a Lei 11.645/2008 na prática. Nos anos subsequentes, muitos documentos fomentaram a implementação da Lei 11.645/2008, como o Plano Nacional de Implementação das Diretrizes Curriculares Nacionais para a Educação das Relações Étnico-Raciais e para o Ensino da História e Cultura Afro- Brasileira e Africana (2008), as Diretrizes Curriculares Nacionais Gerais para a Educação Básica (2010), as Diretrizes Curriculares Nacionais para o Ensino Fundamental de 9 (nove) anos (2010), e as Diretrizes Nacionais para Educação em Direitos Humanos (2012). A temática da diversidade étnica atravessa todos esses documentos que, juntos, fundamentam práticas educativas em diferentes níveis e áreas da educação.

Mas há um documento que destaco aqui por sua relevância, pois está diretamente relacionado à Lei 11.645/2008, que são as suas próprias diretrizes publicadas em 2016, intituladas como "Diretrizes Operacionais para a implementação da história e das culturas dos povos indígenas na Educação Básica, em decorrência da Lei n 11.645/2008". Em termos teóricos, o documento insere a lei no contexto mais amplo das políticas públicas voltadas aos povos indígenas tanto em nível nacional quanto internacional, além de elucidar questões que haviam ficado em aberto desde a sua implementação, em 2008. Por exemplo, as Diretrizes Operacionais da Lei 11.645/2008 evidenciam que a medida se dirige a todas as disciplinas do currículo escolar, inclusive as ciências exatas e biológicas. Além disso, explica que a lei não afeta somente o ensino regular, mas também as universidades, em especial os cursos de formação de professores:

Importa destacar, ainda, que a inserção dos conteúdos referentes a essa temática nos currículos das instituições de Educação Básica 
tem rebatimentos diretos na Educação Superior, principalmente nos cursos destinados à formação de professores, bem como na formação de outros profissionais ligados ao desenvolvimento educacional e cultural. (BRASIL, 2016, p. 4)

Assim, o documento possibilita compreendermos mais detalhadamente a dimensão do alcance da lei, e nesse processo as universidades têm uma responsabilidade importante, principalmente através dos cursos de licenciatura e dos projetos de pesquisa e extensão desenvolvidos pelos laboratórios de todas as áreas do conhecimento.

Outro aspecto abordado pelo documento é a dimensão teórica da lei no que diz respeito ao processo de construção do conhecimento que é, no presente texto, o maior foco de investigação e reflexão, ao menos no que diz respeito ao conhecimento histórico. Nesse sentido, as Diretrizes Operacionais da Lei 11.645/2008 trazem orientações em relação às perspectivas para o ensino dos povos indígenas.

Porém, ainda antes de pensar a dimensão teórica da lei, é importante lembrar que na perspectiva da educação histórica, tanto a Lei 11.645/2008 quanto suas diretrizes devem ser analisadas criticamente. Sendo sua determinação proposta pelo Estado Brasileiro, não podemos esquecer que há uma dimensão nacionalista no bojo de suas orientações. Autores como Peter Lee ressaltam o caráter público e independente do pensamento histórico e, por isso, apesar de a disciplina de história compartilhar princípios importantes com a democracia, há uma independência fundamental entre o conhecimento historiográfico e as propostas de governo, sejam elas quais forem. Em entrevista à Cristiane Bereta da Silva, para a Revista Tempo e Argumento, Peter Lee elabora uma reflexão fundamental quando associa o pensamento histórico aos regimes de governo:

Na verdade a história não é um instrumento para criar certos tipos de cidadãos, não importa o quão nobre tais objetivos pretendam ser. Sua relação com a democracia é muito mais interessante do que isto, a história e a democracia são características de uma sociedade aberta. A história pode ser necessária para o funcionamento bem sucedido de uma democracia, e a democracia pode ser uma forma de arranjo social e 
político que permite a história. Mais importante, a história compartilha alguns valores importantes com a democracia: ela pressupõe liberdade para dar o melhor argumento, ela assume abertura para discussões com base em evidência e ela pressupõe tanto respeito pelas pessoas e igualdade para as pessoas como fontes para discussões. $\mathrm{O}$ aprendizado da história pode provavelmente incentivar alunos a levar a democracia a sério, mas isto está muito longe de significar que o seu papel na educação tem que ser o de um instrumento para produzir democratas. (LEE, 2012, p. 225)

Considerando essa perspectiva, críticas importantes de historiadores em relação à Lei 11.645/2008, incluindo indígenas como Casé Angatu e Edson Kayapó, já foram desenvolvidas e devem ser consideradas no planejamento para o ensino de história a partir da Lei 11.645/2008. ${ }^{1}$ Entre essas críticas estão o modo como o texto da lei se refere aos povos indígenas e de origem africana, como "dois grupos étnicos" (BRASIL, 2008). Tal referência étnica é um grande equívoco, uma vez que somente os povos indígenas são constituídos por centenas de populações diferentes.

Ainda assim, considerar o contexto histórico racial do Brasil, principalmente no que se refere às muitas facetas do racismo, faz com que os pesquisadores do campo do ensino de história interpretem a Lei 11.645/2008 como uma ferramenta de grande importância. Tal ato legislativo é um passo importante para a erradicação do racismo, bem como para o entendimento da diversidade e agência dos povos indígenas no Brasil e nas Américas de modo geral.

\footnotetext{
${ }^{1}$ Ver: SANTOS, Carlos José Ferreira dos [Casé Angatu]. Histórias e culturas indígenas: alguns desafios no ensino e na aplicação da Lei 11.645/2008: de qual história e cultura indígena estamos mesmo falando? História e Perspectivas, Uberlândia, p.179-209, jan./jun. 2015; KAYAPÓ, Edson; BRITO, Tamires. A pluralidade étnico-cultural indígena no Brasil: o que a escola tem a ver com isso? Mneme - Revista de Humanidades, Caicó, v. 15, n. 35, p. 38-68, 2014. Disponível em: https://www.periodicos.ufrn.br/mneme/article/view/7445. Acesso em: 29 ago. 2020.
} 


\title{
Reflexões sobre o pensamento indígena na construção do conhecimento
}

\section{histórico}

Outro aspecto pertinente no que tange às orientações estabelecidas pelas Diretrizes Operacionais da Lei 11.645/2008, diz respeito à metodologia para o ensino de história indígena. A lei não é um acréscimo de conteúdos por eles mesmos, mas propõe o estudo "das diferentes origens culturais da população brasileira", estimulando "um ambiente escolar que permita a manifestação da diversidade de forma criativa e transformadora na superação de preconceitos e discriminações étnico-raciais" (2016, p. 7). É indicado que os estudantes tenham a oportunidade de estabelecer campos de diálogo direto com os povos indígenas, seja pessoalmente (indo a aldeias, em eventos ou convidando representantes indígenas para irem até as escolas e universidades) ou através dos materiais de autoria indígena nos mais diversos formatos:

\begin{abstract}
Uma de suas demandas é a de que os próprios indígenas assumam o protagonismo de falar sobre suas histórias e culturas. Nesse sentido, os sistemas de ensino devem fomentar a publicação de materiais didáticos e pedagógicos sobre a temática de autores indígenas, bem como criar

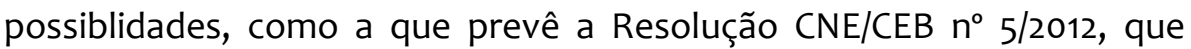
define Diretrizes Curriculares Nacionais para a Educação Escolar Indígena na Educação Básica, de contar com a presença das lideranças indígenas (pajés, xamãs, sábios, intelectuais em geral) nas instituições de Educação Básica como formadores, palestrantes e conferencistas, dentre outras formas de reconhecimento de saberes e conhecimentos indígenas. (BRASIL, 2016, p. 7)
\end{abstract}

A ampliação de publicações autorais indígenas nas últimas décadas vem facilitando essa perspectiva, que também é reconhecida pelos pesquisadores não indígenas como potencial. Especificamente em relação à lei, autores como Angatu, ou os textos que compõem o sétimo volume da publicação "Educação em Rede"2, organizada pelo Sesc e que é constituída majoritariamente de textos de autoria indígena sobre a lei, contribuem ainda mais para que essa metodologia se torne possível na prática.

\footnotetext{
${ }^{2}$ Ver: SESC. Departamento Nacional. Culturas indígenas, diversidade e educação. Rio de Janeiro: Sesc, Departamento Nacional, 2019. v. 7.
} 
Assim, a questão teórica fundamental é que as narrativas indígenas devem constituir o campo da história indígena como documentos históricos que permitam compreender não só as experiências dos povos indígenas no tempo, mas investigar os regimes de historicidades próprios dessas populações. É importante pensarmos em estratégias que viabilizem o estudo da história indígena a partir de seus próprios termos, acessando os aportes conceituais a partir de suas matrizes filosóficas. Estruturas sociais distintas apresentam visões de mundo diferentes das nossas, em que outras categorias são acessadas para a interpretação dos acontecimentos na passagem do tempo. $O$ estudo dos povos indígenas, dessa forma, nos permite compreender as suas motivações históricas e exercita nossa capacidade de entendê-los em sua perspectiva.

Além disso, a proposta de aproximar os saberes indígenas da produção de conhecimento histórico possibilita colocarmos em prática o que entendo como sendo as duas funções principais do ensino de história. A primeira, e talvez a mais evidente, é a sua função social, que considera a herança histórica associada à discriminação racial na formação do Estado Brasileiro. Nesse sentido, a educação é considerada como um dos caminhos possíveis para a erradicação das desigualdades, o que insere a Lei 11.645/2008 no conjunto maior de políticas públicas que objetivam uma reparação histórica.

Já a segunda função diz respeito à importância de instrumentalizar os estudantes com um aporte metodológico e conceitual que lhes permita identificar a participação dos povos indígenas nos processos históricos. Para isso, é preciso que algumas dimensões fundamentais do conhecimento histórico sejam estudadas, como noções referentes à fonte documental, evidência, narrativa, e contexto histórico, além da noção de que existem diferentes escalas (micro e macro-históricas).

Não é o intuito do ensino de história formar pequenos historiadores, e o mesmo vale para o conhecimento em torno dos povos indígenas, e por isso a ideia não é estudar o maior número de documentos possíveis. Ainda assim, é preciso que os alunos entendam dimensões gerais da história indígena. Se há, de um lado, especificidades étnicas que possibilitam inserir cada povo em uma perspectiva regional, de outro existem elementos culturais e experiências que os conectam, tornando possível uma análise dos 
povos nativos nas Américas e até no mundo (povos autóctones), dependendo dos conceitos e escalas utilizados.

Nessa perspectiva, o estudo dos povos indígenas está intrinsecamente ligado ao conhecimento histórico, porém, é preciso que tomemos o cuidado de não projetar nossa própria concepção de história no processo da investigação, pois cada sociedade indígena possui seu regime de historicidade próprio. Essa postura frente à temática indígena não implica o abandono ou a exclusão do aporte conceitual tradicionalmente utilizado pelos historiadores, mas amplia as categorias de análise disponíveis.

Sobre essa perspectiva de considerar os regimes de historicidade indígena na pesquisa e ensino de história, François Hartog é um autor emblemático para abordar este tema. Segundo Hartog, existem princípios meta-históricos que estruturam as experiências dos seres humanos frente à passagem do tempo, os quais denominados como passado, presente e futuro. Há uma ordem no tempo que, porém, não é experienciada ou mesmo organizada da mesma maneira pelos diferentes povos no mundo, e há que se considerar a perspectiva histórica em questão:

Se desde sempre cada ser tem do tempo uma experiência, não visamos aqui considerá-la integralmente, indo do mais vivenciado ao mais elaborado, do mais íntimo ao mais compartilhado, do mais orgânico ao mais abstrato. A atenção, preciso repetir, incide incialmente e, sobretudo, sobre as categorias que organizam essas experiências e permitem revelá-las, mais precisamente ainda, sobre as formas ou os modos de articulação dessas categorias ou formas universais, que são o passado, o presente e o futuro. (HARTOG, 2014, p. 38)

Cada contexto é impulsionado por uma ordem específica pois ela depende de uma perspectiva social, por isso a referência ao termo "regime" expressa essa determinação ou particularidade compartilhada por um grupo de pessoas em um intervalo específico de tempo. Já "historicidade" indica o modo como esse tempo é experienciado, quais categorias são impulsionadas para dar sentido ao vivido e que, independentemente de como o seja, tem legitimidade histórica. 
Autores como Carlos Fausto, Michael Heckenberger, Ailton Krenak, Gersem Baniwa e Maria Regina Celestino de Almeida, refletem sobre aspectos do pensamento indígena que caminham na mesma direção de Hartog quando pensa os regimes de historicidade. Cada um à sua maneira e a partir de seu campo de análise, os autores entendem que as epistemologias indígenas devem ser levadas em consideração no processo de construção de conhecimento. Almeida (2019, p. 117) entende que devemos considerar os "esquemas mentais" próprios dos indígenas para o estudo dos contextos históricos, cuidando para não projetarmos categorias externas de forma mecânica.

Fausto e Heckenberger, assim como Hartog, entendem que a experiência no tempo indica necessariamente processos de transformação e permanência (passado, presente e futuro) e que para investigar os contextos indígenas é preciso considerar o modo como o pensamento indígena se constitui e se expressa. Nesse sentido, os autores apontam algumas possibilidades para darmos início à investigação:

The construction of kinship and the meaningful experiences of dwelling have been treated as key elements of indigenous historicities. [...] ritual has been studied as a primary means of producing and actualizing social memory [...] a theme that has acquired a more theoretical formulation in the works of Carlo Severi (1993, 2004). Narratives - whether "mythical", "historical", or "autobiographical" - and other verbal genres have been investigated, revealing singular ways of constructing temporality, as well as the inscription in historical events in discursive forms [...]. (FAUSTO; HECKENBERGER, 2007, p. 11, grifo do autor)

Desde a paisagem aos rituais, até as relações de parentesco e as narrativas míticas, todos esses são aspectos que nos dizem sobre a passagem do tempo. Para acessar o pensamento indígena, podemos utilizar o método etnográfico, mas também os textos de sua autoria, muitos dos quais apresentam conceitos e interpretações de sua própria perspectiva. Essa segunda opção, a de pesquisar a partir da escrita indígena, parece ser ainda mais acessível ao ensino de história, uma vez que a etnografia (ou uma breve visita a uma aldeia) nem sempre são atividades possíveis dependendo do contexto em que a escola está inserida. 
Assim, trago um exemplo pensando um aspecto conceitual do pensamento indígena a partir de dois autores mencionados acima, que são Krenak, na obra Ideias para adiar o fim do mundo e Baniwa, no artigo Direitos Humanos e Direitos Indígenas na Perspectiva da Lei n. 11.645/2008. O foco recai aqui sobre o modo como pensam as dimensões do conceito de humanidade na perspectiva indígena em contraponto ao pensamento ocidental. Trazer as reflexões conceituais desenvolvidas pelos dois autores tem como objetivo demonstrar o quanto é possível aprender e dialogar com os saberes indígenas a partir de suas produções, com atenção especial às conexões possíveis entre esses conhecimentos e o ensino de história.

Em relação ao texto de Krenak, o autor reflete sobre os tipos de relações que os sujeitos estão estabelecendo com o território em um contexto de globalização, em que a velocidade e facilidade de deslocamento estão associadas a uma ausência de pertencimento e responsabilidade com os seus territórios de origem. Por sua vez, isso ocorre porque a globalização, como a conhecemos, está associada ao sistema neoliberal, o que estimula a configuração das relações entre seres humanos e não humanos a partir da chave do consumo e da objetificação. Em contraponto a essa perspectiva, ele apresenta aspectos culturais de seu próprio povo, os Krenak:

O rio Doce, que nós, os Krenak, chamamos de Watu, nosso avô, é uma pessoa, não um recurso, como dizem os economistas. Ele não é algo de que alguém possa se apropriar; é uma parte da nossa construção como coletivo que habita um lugar específico, onde fomos gradualmente confinados pelo governo para podermos viver e reproduzir as nossas formas de organização (com toda essa pressão externa). (KRENAK, 2019, p. 21)

Assim, o território é morada dos parentes que são, por exemplo, o rio Doce, seres não humanos que apresentam características que comumente nós, não indígenas ou "brancos", associamos aos seres humanos ou às pessoas, para utilizar as palavras de Krenak. Se, neste contexto, o rio Doce é um avô, aqui nos é apresentada uma outra concepção de humanidade e, inclusive, de agência pois, sendo um parente, o rio possui 
características de personalidade e atua no cotidiano da comunidade constituindo as relações de parentesco. O autor segue dando outros exemplos:

No Equador, na Colômbia, em algumas dessas regiões dos Andes, você encontra lugares onde as montanhas formam casais. Tem mãe, pai, filho, tem uma família de montanhas que troca afeto, faz trocas. $E$ as pessoas que vivem nesses vales fazem festas para essas montanhas, dão comida, dão presentes, ganham presentes das montanhas. Por que essas narrativas não nos entusiasmam? Por que elas vão sendo esquecidas e apagadas em favor de uma narrativa globalizante, superficial, que quer contar a mesma história para a gente? (KRENAK, 2019, p. 10)

A partir da narrativa de Krenak é possível identificar que os sentidos dados às relações sociais, de identidade, território, parentesco e humanidade são diferentes de como nos acostumamos a pensar no fazer historiográfico e, como ele bem pontua, em um contexto neoliberal globalizante. Por isso, o seu entendimento sobre a globalização é importante, pois indica esse sentido hegemônico da construção do conhecimento, em que saberes ocidentais se colocam enquanto universais e silenciam outras filosofias. Essa mesma universalidade está atrelada a um neoliberalismo que objetifica o território e, consequentemente, despersonaliza as relações de parentesco entre humanos e outros seres.

A crítica de Krenak à globalização neoliberal é bem próxima da apresentada por Fausto e Heckenberger, que também partem dos saberes indígenas para elaborar suas análises, mais especificamente dos povos amazônicos. Ambos pontuam a influência da globalização no modo como a antropologia e a história vêm pensando suas categorias de análise, como agência e indivíduo. Para os autores, a categoria agência não é utilizada com cuidado, mas quase sempre como sinônimo de uma suposta capacidade humana (homo sapiens) que se pretende universal. Nessa perspectiva, os humanos são apresentados como seres facilmente passíveis de transformar a realidade, rompendo fronteiras e sendo criativos. Concordo com os autores quando entendem que essa definição mais popularizada dialoga com o atual sistema neoliberal, no qual a ideia de ação e a criatividade humanas estão associadas a um contexto de consumo que, apesar 
de parecer amplamente acessível, é um lugar restrito de privilégio econômico e político. A utilização de agência nos termos expressos não dá conta de pensar as diversas experiências dos sujeitos no mundo que são, como demonstra Krenak, bem mais diversas:

In terms of the topics covered by this book, the tension between a New Amazonian History and a New Amazonian Ethnography is expressed in the way the category of 'agency' is claimed by each line of research. Use to define the creative capacity to act in a transformative on sociocultural reality, agency has been taken either as universal human quality - one previously ignored by structural anthropology [...]. (FAUSTO; HECKENBERGER, 2007, p. 12, grifo do autor)

É importante perceber que a crítica não é direcionada aos sentidos atribuídos ao conceito de agência, mas quando eles são utilizados partindo do pressuposto de uma universalidade. Essa postura silencia outras concepções de agência. Penso, inclusive, que essa questão implique mais diretamente na vida dos sujeitos, pois essas atribuições de sentido interferem na materialidade das relações humanas, como na luta dos povos indígenas por seus territórios tradicionais.

Em seu texto que reflete acerca da noção contemporânea de direitos humanos, Baniwa também mobiliza o conceito de humanidade de um modo que se aproxima dos conceitos tratados por Krenak, ao apresentar as distinções que constituem o conceito de humanidade, ou como ele também chama, de "gente", no pensamento indígena em relação ao ocidental. A definição de humano não está associada a uma forma única de corpo ou materialidade, organicamente pré-estabelecida. Se trata de uma condição do momento, chamada pelo autor de "estado de espírito":

Segundo essas cosmologias seria mais adequado falar em estar humano, do que ser humano por se tratar de um estado possível e sempre transitório. Os seres e as coisas possuem capacidades de transformação. Tanto os humanos podem transformar-se em animais ou coisas quanto os animais ou coisas podem transformar-se em humanos. Isto desde a criação do mundo. Vários clãs indígenas recebem a denominação de certos animais que indicam sua potência de estado de mira-sä, por 
exemplo, "gente onça". As pessoas do clã "Gente Onça" têm a potência de se transformar em onça. (BANIWA, 2019, p. 84, grifo do autor)

Pensar no humano como uma punção que leva a um estado de espírito torna, nesta perspectiva, o conceito de humanidade atrelado às ideias de transformação, transitoriedade e potência, que impulsionam e deslocam esse estado, e que pode se apresentar a partir de diferentes materialidades, em diferentes corpos e formas. Inclusive, neste caso, Baniwa traz mais um elemento para esse debate em torno da categorização de humanidade, pois para além das espécies de animais e outros seres da floresta, ele pontua a possibilidade de atuação das “coisas”, os objetos. Porém, é importante notar que a condição humana no sentido proposto pelos autores se dá a partir de regras específicas às diferentes sociedades indígenas, e não de modo aleatório.

Assim, os conceitos de humano, ou "pessoa" para Krenak, e "gente" segundo Baniwa, exemplificam o modo como as relações são pensadas na dimensão indígena, que Baniwa denomina como "cosmopolítica" ou "cosmocêntrica", o que implica a interdependência entre os seres, sem hierarquização estática das relações entre eles, uma vez que todos vivem "a mesma ordem de existência”3 (BANIWA, 2019, p. 84):

Ou seja, nenhum ser ou coisa é superior a outro em termos de possibilidade, capacidade ou potência de existência. Este princípio é o que fundamenta e explica a relação vital ou fatal dos povos indígenas com os seus territórios, aqui entendidos como natureza ou cosmo. (BANIWA, 2019, p. 84)

Além disso, tanto Baniwa quanto Krenak reiteram que essas relações não se dão independentes do tempo e do espaço, pois ocorrem no território tradicional, onde essas humanidades são agenciadas. Penso que seja por esse caminho que Hartog proponha o estudo dos regimes de historicidade, entendendo quais e como as categorias de análise

\footnotetext{
3 Outras definições para o conceito de humanidade não se limitam, evidentemente, aos Krenak ou aos Baniwa. Para saber mais sobre esse tema em relação a outros povos indígenas, ver: FAUSTO, Carlos, HECKENBERGER, Michael (eds). Time and memory in indigenous Amazonia: anthropological perspectives. Gainesville: University Press of Florida, 2007.
} 
fazem sentido para os diferentes grupos sociais, sendo a própria concepção de humanidade parte do conjunto de categorias pertinentes à análise das estruturas sociais.

Assim, o estudo dos saberes indígenas e seus conceitos no ensino de história é um caminho potencial para a ampliação do aporte instrumental na análise dos documentos por parte dos alunos. Mas, na prática, a questão é sempre mais complexa. Especificamente sobre o ensino de história, Lee salienta a importância de atentarmos não só para os conteúdos em si, mas para os processos que envolvem a própria aprendizagem do conhecimento histórico em termos cognitivos. Estudar história é diferente de estudar outros tipos de conhecimento, como as ciências exatas e biológicas, que dispõem de outras metodologias e arranjos mentais para interpretar os dados.

Ao investigar a educação formal, pesquisas realizadas por quase quatro décadas no Reino Unido, e posteriormente na América do Norte e em outras regiões da Europa com crianças e adultos, podem nos trazer alguns indícios de como se dá a relação dos alunos com o conhecimento histórico. As investigações indicam que o pensamento histórico pode estar distante do modo como os sujeitos se relacionam com o tempo na vida prática. Segundo Lee, dentre as respostas para essa hipótese está o significado que os alunos dão ao que é considerado verdadeiro ou falso, questão fundamental no estudo da História. A ideia de verdade, por exemplo, aparece atrelada às figuras de autoridade, como os pais:

Os critérios do que conta como "a verdade" são compartilhados (ou, pelo menos, fixados por uma autoridade) para que o passado possa parecer ser o critério da verdade. Mas é claro que o que dizemos sobre o passado da história é uma construção com base na evidência - não há passado fixo disponível com um controle sobre o que dizemos sobre ele. E porque os relatos históricos não são cópias do passado, mas compartilham algumas das características de ambas as metáforas e teorias, não pode haver mais de um relato sobre "a mesma coisa", sem um ser necessariamente falso ou distorcido. (LEE, 2016, p. 117, grifo do autor)

Essa possibilidade, no que diz respeito à relação da verdade com as figuras de autoridade na vida dos alunos, pode levar ao entendimento de que somente um tipo de 
relato, uma única versão narrativa é capaz de explicar os acontecimentos. Nesse caso, o professor de História tem alguns desafios pela frente, que não devem desconsiderar essa e outras experiências prévias dos alunos.

Relacionando esse processo de pensar à bagagem que os alunos já possuem, mais especificamente ao contexto brasileiro e à Lei 11.645/2008, penso que, além da relação com a verdade, é indispensável considerarmos a presença de estereótipos e desinformação sobre os povos indígenas como dado histórico pertinente. Há que se considerar que nossa base epistemológica de cunho eurocêntrico dificulta a abertura para o diálogo sobre os povos indígenas. Para encarar este obstáculo, indígenas e não indígenas engajados com o ensino de história entendem que, antes de tudo, é preciso compreender os tipos de estereótipo com que estamos lidando, como as representações e significados mais comumente associados aos povos indígenas no senso comum. Somente a partir desse entendimento poderemos, aos poucos, construir campos de diálogo que possibilitem posteriormente um estudo mais profundo das estruturas sociais indígenas. Baniwa, sabiamente, chamou esta etapa da implementação da Lei 11.645/2008 como uma fase de deseducação de nossos preconceitos:

Essa desconstrução de pré-conceitos é uma verdadeira deseducação, ou seja, aprender a reconhecer os erros aprendidos na própria escola. Só depois do processo de deseducação será mais fácil uma nova reeducação com base em novos princípios e visões de mundo capazes de construir uma nova realidade social, cultural, econômica, política e espiritual menos eurocêntrica e com lugares para todos os povos, culturas e saberes com os quais a escola trabalha, os quais ela precisa valorizar e dar conta. (BANIWA, 2012, p. 141)

Dialogando com a reflexão do autor, as distorções criadas ao longo da história sobre os povos indígenas vão muito além do espaço da escola, e perpassam todas as esferas sociais. Na prática, o que muitos pesquisadores têm feito para lidar com essa realidade é analisar o que já foi produzido sobre o tema nas escolas, como através dos materiais didáticos, possibilitando uma análise mais precisa das questões urgentes a serem trabalhadas. 


\section{Considerações Finais}

Como bem pontuam as Diretrizes Operacionais da Lei 11.645/2008, aspecto que também é reforçado por Baniwa, o ensino de história indígena não diz respeito a um estudo de conteúdos por si só, mas aos "os fundamentos cosmológicos, filosóficos e epistemológicos que orientam as diferentes cosmovisões e o estabelecimento dos direitos humanos na contemporaneidade" (BANIWA, 2019, p. 84). O acesso às narrativas indígenas e o comprometimento em estabelecer um diálogo entre seus saberes e o conhecimento histórico é um dos pilares centrais para a implementação da Lei $11.645 / 2008$.

Procurei demonstrar que um dos caminhos possíveis para a elaboração desse objetivo é o estudo das categorias indígenas, que permitem compreendermos o modo como as relações humanas são construídas no tempo. Como os conceitos são ferramentas históricas, é plenamente possível aos historiadores aprendê-los a partir do que é pensado pelos indígenas. Mais do que isso, o estudo das categorias indígenas não precisa ser acionado somente no estudo dessa temática, mas também de outros contextos históricos em que seu uso se demonstre frutífero.

O fato de as relações entre humanos e outras espécies e entidades se darem de formas muito diferentes de como concebemos no pensamento ocidental e eurocentrado, é um exemplo de que não é possível estudar os povos indígenas profundamente silenciando suas epistemologias. Prova disso é a própria noção de humanidade ser uma condição momentânea e um estado de espírito para algumas populações, como vimos com Baniwa, ou fazerem parte das relações de parentesco, no caso dos Krenak.

Por isso, o estudo dos conceitos como o de humanidade(s) indígena(s) tem muito a dialogar e ensinar à história, que é fundamentalmente um campo de conhecimento que se propõe a pensar as experiências humanas no tempo. Isso nos permite pensar, por exemplo, como o entendimento de humanidade vem sendo pensado na história e o quanto o uso indiscriminado dessa e de outras muitas categorias de análise dificultam o nosso entendimento sobre as histórias das populações no mundo, como é o caso das indígenas. 


\section{Referências}

ALMEIDA, Maria Regina Celestino. História indígena: teorias, fontes e métodos em perspectiva interdisciplinar. In: REIS, Tiago Siqueira; SOUZA, Carla Monteiro de; OLIVEIRA, Monalisa Pavonne; JÚNIOR, Américo Alvez de Lyra. Coleção história do tempo presente. Boa Vista: Editora da UFRR, 2019. v. 1. p. 112-130.

BANIWA, Gersem. Direitos humanos e direitos Indígenas na Perspectiva da Lei n. 11.645/2008. In: EDUCAÇÃO EM REDE: culturas indígenas, diversidade e educação. Rio de Janeiro: Sesc, Departamento Nacional, 2019. v. 7. p. 82-105.

BANIWA, Gersem. Gersem José dos Santos Luciano - Gersem Baniwa. [Entrevista cedida a] Maria Aparecida Bergamaschi. Revista História Hoje, Pelotas, v. 1, n. 2, p. 141, 2012. Disponível em: https://rhhj.anpuh.org/RHHJ/article/view/44. Acesso em: 05 mar. 2021.

BRASIL. [Constituição (1988)]. Constituição da República Federativa do Brasil. Organizado por Ilana Trombka. Brasília: Senado Federal, 2016. 498 p.

BRASIL. Diretrizes Operacionais para a implementação da história e das culturas dos povos indígenas na Educação Básica, em decorrência da lei n. 11.645/2008. [Brasília: Presidência da República], 2016.

BRASIL. Lei n. 11.645, de 9 de janeiro de 2003. Altera a lei no 9.394, de 20 de dezembro de 1996, modificada pela lei $\mathrm{n}$ - 10.639, de 9 de janeiro de 2003, que estabelece as diretrizes e bases da educação nacional, para incluir no currículo oficial da rede de ensino a obrigatoriedade da temática "história e cultura afro-brasileira e indígena". [Brasília: Presidência da República], 10 mar. 2008.

FAUSTO, Carlos, HECKENBERGER, Michael (eds). Time and memory in indigenous Amazonia: anthropological perspectives. Gainesville: University Press of Florida, 2007.

HARTOG, François. Regimes de historicidade: presentismo e experiências do tempo. Belo Horizonte: Autêntica, 2014.

IBGE - Instituto Brasileiro de Geografia e Estatística. Os indígenas no censo demográfico 2010: primeiras considerações com base no quesito cor ou raça. Rio de Janeiro, 2012.

KRENAK, Ailton. Ideias para adiar o fim do mundo. 2. ed. São Paulo: Companhia das Letras, 2019. 
LEE, Peter. Literacia histórica e história transformativa. Educar em Revista, Curitiba, Brasil, n. 60, p. 107-146, 2016. Disponível em: https://revistas.ufpr.br/educar/article/view/45979. Acesso em: 27 ago. 2020.

LEE, Peter J. O ensino de história: algumas reflexões do Reino Unido: entrevista com Peter J. Lee. [Entrevista cedida a] Cristiane Bereta da Silva. Revista Tempo e Argumento, 9.394/1996 Florianópolis, v. 3, n. 2, p. 216-250, 2012. Disponível em:

http://www.revistas.udesc.br/index.php/tempo/article/view/2175180304022012216. Acesso em: 27 ago. 2020.

Recebido em: 30/10/2020 Aprovado em: 29/03/2021

Universidade do Estado de Santa Catarina - UDESC Centro de Ciências Humanas e da Educação - FAED

Volume 22 - Número 48 - Ano 2021 revistapercursos@gmail.com 